\title{
The Canadian Digestive Health Foundation research program
}

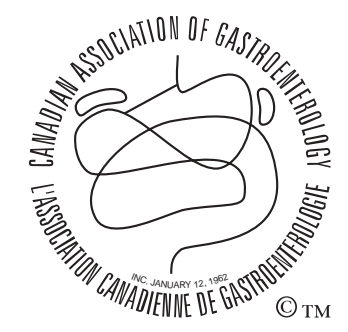

En français voir page 647

Stephen Vanner MD FRCPC M Sc Canadian Digestive Health Foundation Research Committee

Since its inception in the early 1990s, the Canadian DDigestive Health Foundation (CDHF) (then the Canadian Digestive Disease Foundation) has been dedicated to promoting high quality research into gastrointestinal (GI) health and disorders. To meet this goal, the Foundation designed a program to attract bright and enthusiastic investigators with innovative ideas who needed funding to initiate their research.

Between 1995 and 1999, the CDH F funded seven young investigators who have become key members of the
Canadian GI research community. In 2001, as a result of sponsorship from pharmaceutical industry partners, the Canadian Institutes of $\mathrm{H}$ ealth Research ( $\mathrm{CIHR}$ ) and the $C$ anadian $A$ ssociation of $G$ astroenterology ( $C A G)$, three awards were issued: the CDHF-CAG-CIHR/A bbott Helicobacter 0 perating G rant, the CDH F-CA G-CIH R/Byk $\mathrm{New}$ Investigator Establishment $\mathrm{G}$ rant and the CDHF/A straZeneca Fellowship (Table 1).

This year, the Foundation is very pleased to have considerably expanded its program in digestive disease research

\section{TABLE 1}

Past recipients of Canadian Digestive Health Foundation (CDHF) research awards

\begin{tabular}{llll}
\hline Year & Research award & Recipient & Institution \\
\hline 1995 & CDHF Grant & Dr Carlo Fallone & McGill University, Montreal, Quebec \\
1996 & CDHF Grant & Dr Johane Allard & University of Toronto, Ontario \\
1997 & CDHF Grant & Dr Claude Asselin & Université de Sherbrooke, Quebec \\
1997 & CDHF Grant & Dr DSR Sarma & University of Toronto, Ontario \\
1998 & CDHF Grant & Dr Brenda L Coomber & Guelph University, Ontario \\
1998 & CDHF Grant & Dr Winnie WS Wong & University of Alberta, Edmonton \\
1999 & CDHF Grant & Dr Nicola Jones & University of Toronto, Ontario \\
2001 & CDHF/AstraZeneca Fellowship & Dr Jia-Qing Huang & McMaster University, Hamilton, Ontario \\
2001 & CDHF-CAG-CIHR/Abbott Helicobacter & Dr Anne Marie Salapatek & University of Toronto, Ontario \\
2001 & Operating Grant & & University of Calgary, Alberta \\
& CDHF-CAG-CIHR/Byk & Dr Nathalie Vergnolle & \\
\hline
\end{tabular}




\section{TABLE 2}

Recipients of the 2002 Canadian Digestive Health Foundation (CDHF) research awards

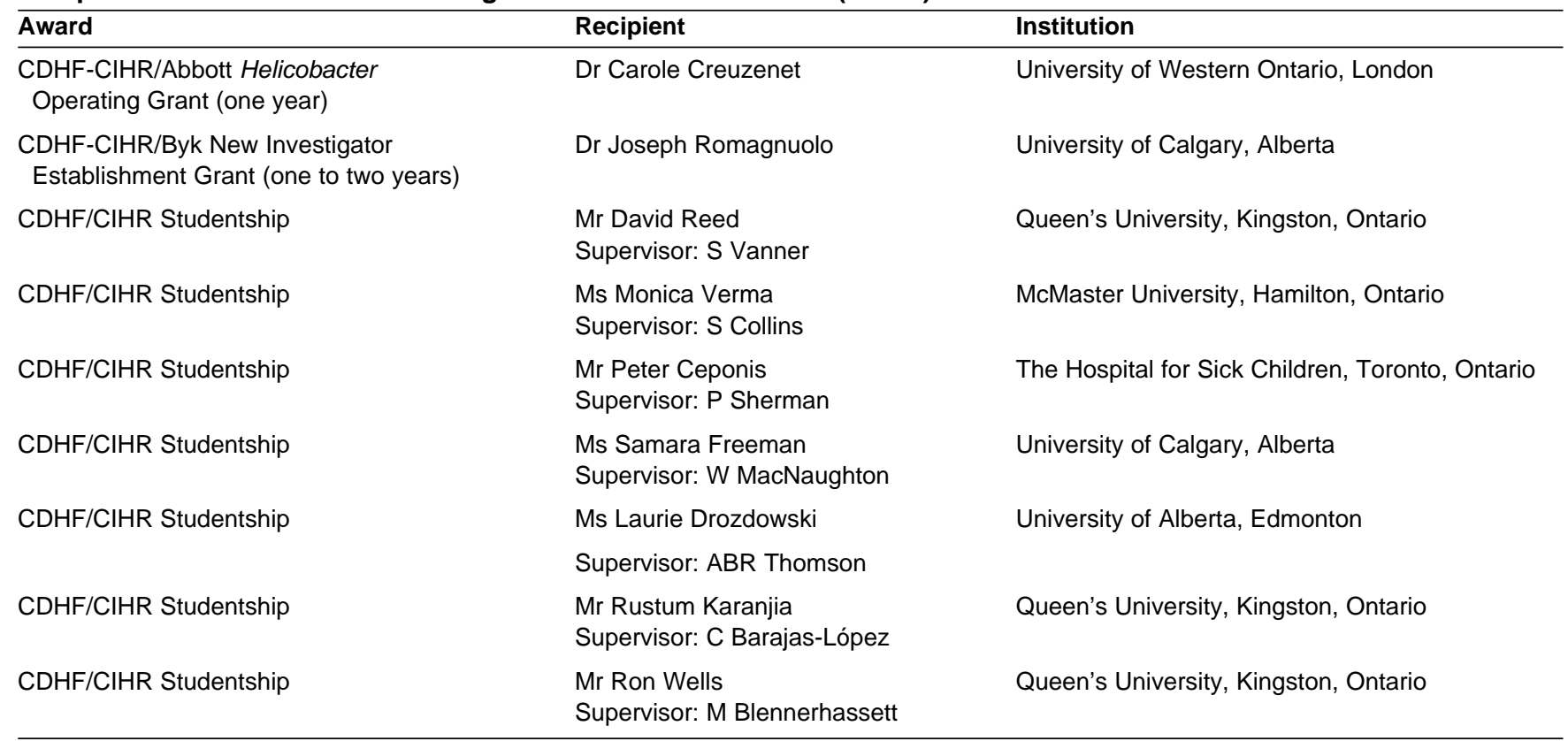

CIHR Canadian Institutes of Health Research

(Table 2). For the second consecutive year, the CDHF$\mathrm{CIHR/A}$ bbott Helicobacter $O$ perating $\mathrm{G}$ rant and the CDHF-CIHR/Byk New Investigator Establishment Grant were awarded. Congratulations to $\mathrm{Dr} C$ arole $\mathrm{C}$ reuzenet, of the University of Western Ontario, London, and to $\mathrm{Dr}$ Joseph Romagnuolo, of the University of Calgary, Alberta, respectively. Offered for the first time were CDHF/CIHR studentships for M asters and Doctoral students. A total of seven studentships were awarded - three funded fully by CIHR, and four jointly funded by the CIHR and the CDHF. The CDHF applauds the successful young scientists listed in Table 2. A complete detailed listing of all awards can be found on the C DH F W eb site (www.cdhf.ca).
In July 2002, the Foundation circulated a call for proposals for two CDHF/A straZeneca fellowships. Please contact the CDHF National Office (e-mail: colhfoffice@cdhf.ca) for additional information.

These grants, fellowships and studentships represent a significant investment both in research and in Canada's most promising $\mathrm{GI}$ scientists. The CDHF gratefully acknowledges the generous financial support of $A$ bbott Laboratories Ltd, A straZeneca C anada Inc, Byk C anada Inc and the CIHR that made this possible. In 2003, the Foundation looks forward to obtaining similar or increased research funding, with the commitment of existing and new co-sponsors. 


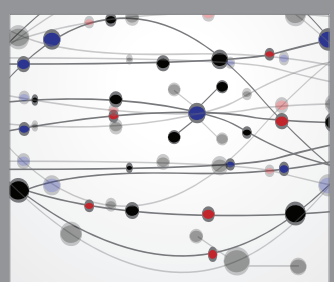

The Scientific World Journal
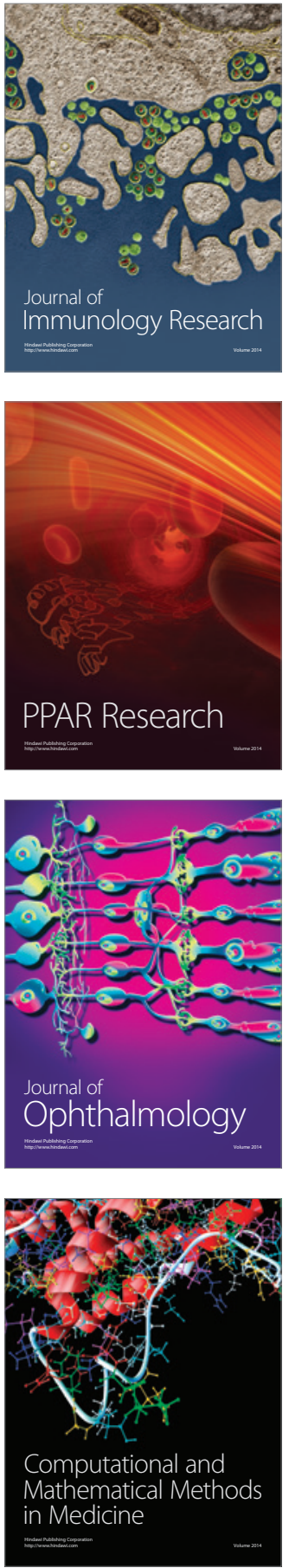

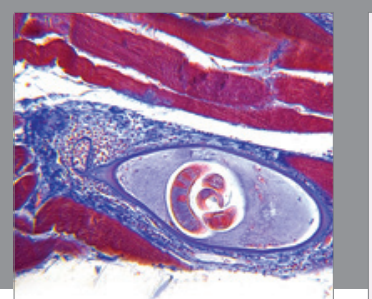

Gastroenterology Research and Practice

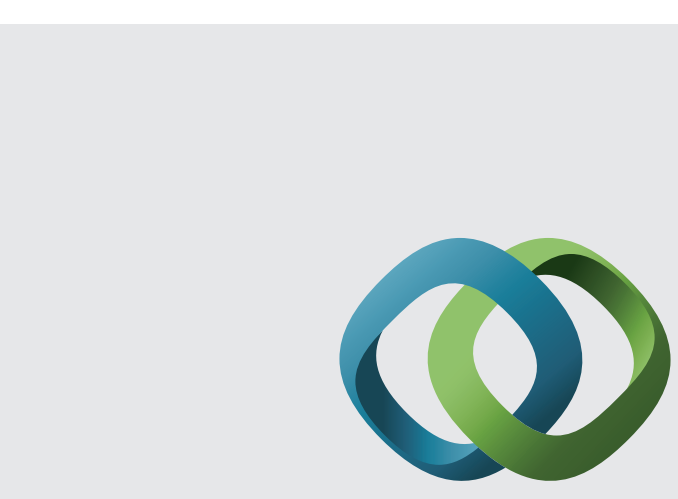

\section{Hindawi}

Submit your manuscripts at

http://www.hindawi.com
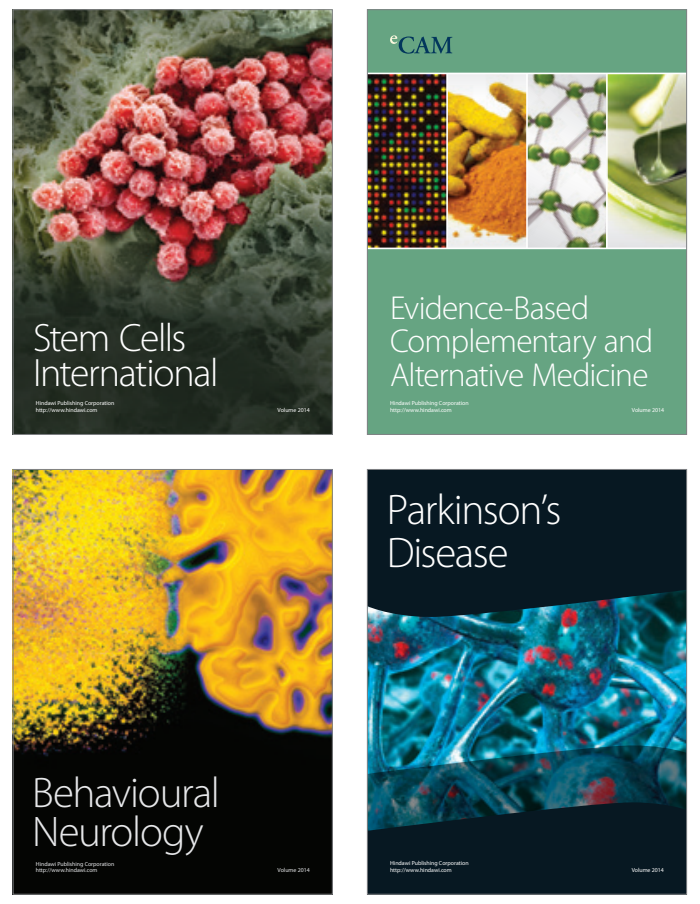
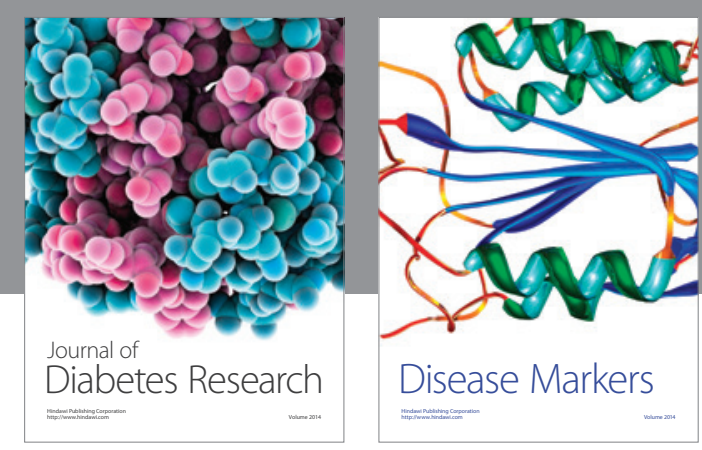

Disease Markers
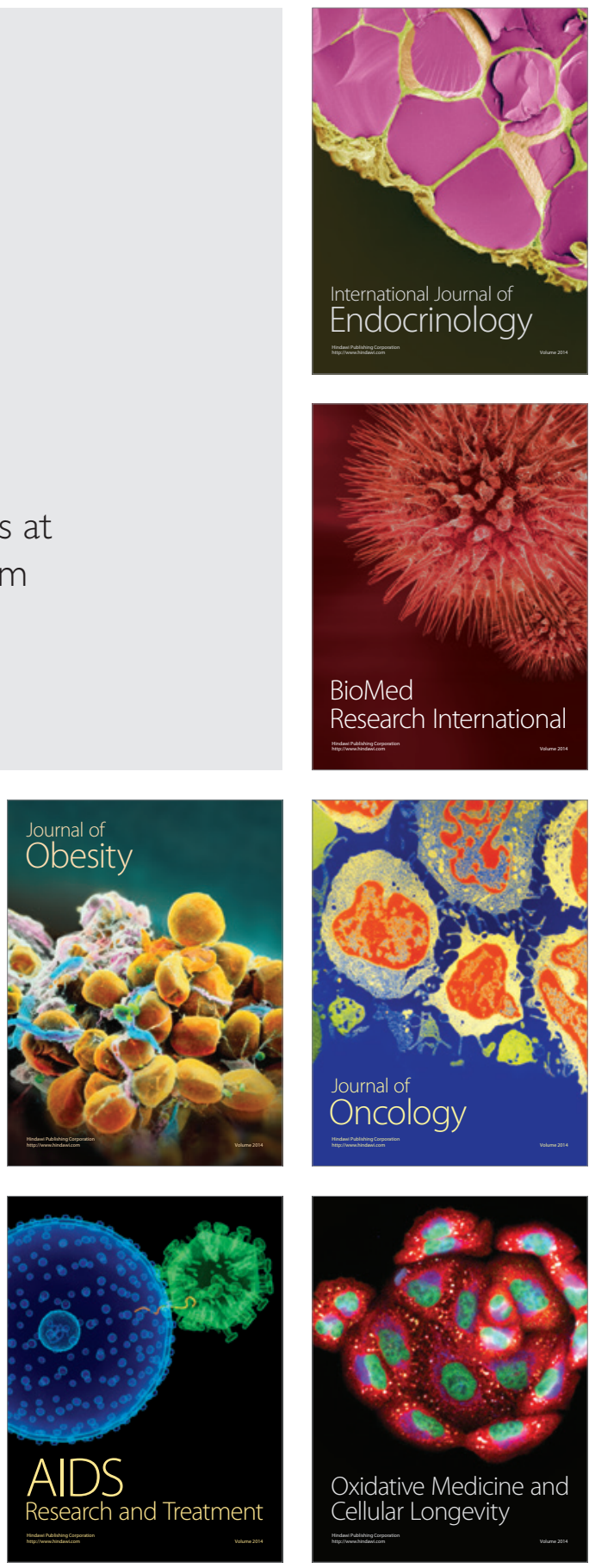